Journal of Pharmacy Practice and Community Medicine.2018, 4(3):137-143• http://dx.doi.org/10.5530/jppcm.2018.3.33

e-ISSN: 2455-3255

\title{
Can Diabetes Self-Management Program Improve Patients' Knowledge? A Real Life Evaluation Study of Lebanese Diabetic Adults
}

\author{
Abeer El-Haddam ${ }^{1 *}$, Souheil Hallit ${ }^{2,3,4,5,6,7}$, Etwal Bou Raad ${ }^{1}$ \\ ${ }^{1}$ Department of Pharmaceutical Sciences, Faculty of Pharmacy, Lebanese International University, Beirut, LEBANON. \\ ${ }^{2}$ Faculty of Pharmacy, Lebanese University, Beirut, LEBANON. \\ ${ }^{3}$ Faculty of Pharmacy, Saint-Joseph University, Beirut, LEBANON. \\ ${ }^{4}$ Faculty of Medicine and Medical Sciences, Holy Spirit University of Kaslik (USEK), Jounieh, LEBANON. \\ ${ }^{5}$ Research Department, Psychiatric Hospital of the Cross, P.O Box 60096, Jal Eddib, LEBANON. \\ ${ }^{6}$ Occupational Health Environment Research Team, U1219 BPH Bordeaux Population Health Research Center Inserm - Université \\ de Bordeaux, Bordeaux, FRANCE. \\ ${ }^{7}$ INSPECT-LB: Institut National de Sante Publique, Epidemiologie Clinique et Toxicologie, Faculty of Public Health, Lebanese \\ University, Beirut, LEBANON.
}

Received: 23 July 2018;

Accepted: 23 August 2018

*Correspondence to:

Abeer EL-Haddam,

Lebanese International University, School of Pharmacy, P.O. Box: 146404, Mouseitbeh, Beirut, LEBANON.

Email: a.haddam@hotmail.com

Copyright: (C) the author(s),publisher and licensee Indian Academy of Pharmacists. This is an open-access article distributed under the terms of the Creative Commons Attribution Non-Commercial License, which permits unrestricted non-commercial use, distribution, and reproduction in any medium, provided the original work is properly cited.

\begin{abstract}
Objectives: The objective was to assess the effect of the Advanced National Standards for DSME program in improving the knowledge of Lebanese elderly diabetic patients. Secondary objectives were to test the influence of pharmacist counseling on managing these patients' lifestyle and assess health perceptions that affect diabetic patients for effective management through the Health Belief Model (HBM). Methods: This cross-sectional study, conducted from February until May 2016 in different community pharmacies, enrolled 206 patients. Results: All knowledge items scores increased significantly from pre to post counselling $(p<0.05$ for all variables). Female gender significantly increased the knowledge score (Beta= $0.625 ; p=0.001$ ), whereas living with a family member significantly decreased the knowledge score (Beta= $0.975 ; p=0.02$ ). Regarding patient perception on the health belief model, the susceptibility score was significantly and positively correlated with the severity score and the benefits score $(r=0.259$ and $r=0.680)$ respectively, but negatively correlated with the barriers score $(r=-0.290)$. Moreover, the severity score was significantly correlated with the benefits score $(r=0.230)$, whereas the benefits score was significantly but negatively correlated with the barriers score $(r=-0.311)$. Conclusion: This study has demonstrated that a formal diabetes education program can effectively increase patients' diabetes knowledge and will heighten patient knowledge about the disease and its complications.
\end{abstract}

Key words: DSME, Health belief model, Education, Program, Diabetes mellitus.

\section{INTRODUCTION}

The Word Health Organization (WHO) announced in the World Health Day (2016), the need to beat diabetes, since the number of people with diabetes mellitus (DM) has almost quadrupled from 108 million in (1980) to 422 million (i.e.: 1 person in 11 has diabetes) in 2014. ${ }^{[1]}$ As type 2 diabetes accounts for $90-95 \%$ of all diabetes, ${ }^{[2]}$ driven by factors including overweight (appears 1 in every 3 people) and obesity (appears 1 in every 10 people). ${ }^{[1]}$ Also, 1.5 million deaths are directly attributed by diabetes each year, ${ }^{[1]}$ leading to be the $7^{\text {th }}$ cause of death worldwide in $2030 .^{[3]}$

Furthermore, according to the International Diabetes Federation (IDF) Diabetes Atlas $7^{\text {th }}$ edition, the number of people living with diabetes in MENA (Middle East and North Africa) region is expected to double in the next 25 years from 35.4 million $(\approx 9.1 \%$ of adults) in $(2015)$ to 72.1 million in (2040). A systematic review on the prevalence of type 2 diabetes in the Gulf Cooperation Countries (GCC) showed that five out of the world's top ten countries for highest diabetes prevalence are in the MENA region, ${ }^{[4]}$ in agreement with the IDF findings; these findings make type 2 diabetes an important cause of morbidity and mortality in this region, with the highest global prevalence ranging from $8 \%$ to $24 \% .{ }^{[5-6]}$ In 2015 , IDF estimates that four out of ten adults $(>40.6 \%)$ with diabetes are undiagnosed in the MENA region, with the majority $(83.9 \%)$ of them living in low- or middle- income countries. ${ }^{[4]}$ As for Lebanon, according to IDF (2011), Lebanon was included in the six of the top 10 countries with the highest prevalence of diabetes in adults $\left(<80\right.$ years) in the Arab region $(20.2 \%) .{ }^{[7]}$

The Diabetes Self-Management Education (DSME) is the continuing practice of simplifying knowledge, skills and ability essential for diabetes care. This process incorporates the needs, goals and life experiences of the person with diabetes. Its global aims are to support the patient's informed decision-making, self-care behaviors, problem solving and active relationship with the health care professional in order to improve clinical outcomes, health status and quality of life in a cost-effective manner. ${ }^{[8]}$ In addition, it maintains behaviors that can prevent or delay the onset of diabetes in people with pre-diabetes. ${ }^{[9-10]}$ Many studies showed that the effect of a diabetes counselling program on knowledge, attitude and practice among 


\section{El-Haddam, et al.: DSME and Diabetic Patients' Knowledge}

diabetics and the effectiveness of a community pharmacist intervention in diabetes care worldwide and in the Arab countries improved perception about disease, diet, lifestyle changes, glycemic control, self-management and knowledge. ${ }^{[11-13]}$

No studies were conducted in Lebanon to study the pharmacists' role in improving self-knowledge and perception about diabetes mellitus according to the standardized program. The primary outcome for this study was to assess the effect of the Advanced National Standards for DSME program in improving the knowledge of the Lebanese outpatient elderly diabetic patient. Secondary objectives were to test the influence of pharmacist counseling on managing the lifestyle in patients with diabetes mellitus in Lebanese regions and to assess the patient health perceptions that affect diabetic patients for effective management.

\section{METHODS \\ Sample size calculation}

A sample of 204 patients was initially targeted to allow for adequate power for this analyses to be carried out based on a population size of four million inhabitants in Lebanon, a $15.8 \%$ expected frequency of diabetes ${ }^{[14,15]}$ and a $5 \%$ confidence limits. ${ }^{[16]}$ The non- response rate was (26.4\%); 280 patients were approached, 206 agreed to participate.

\section{Study Design}

A cross-sectional study was conducted from February until May 2016 in different community pharmacies from all districts in Lebanon. A pre- and post- questionnaire, developed by the authors based on previous DSME studies done in other countries but adapted to the Lebanese society, was used to evaluate program effectiveness. Since this evaluation design aim is to evaluate the program at community settings, we have excluded critical ill patients or hospitalized patients. Patients were invited to participate in this program either at outpatient clinics or community pharmacies from two Lebanese governorates.

\section{Intervention Components}

A direct patient counseling session using a leaflet that includes pictures, tables and factual information about diabetes symptoms and complications. In addition, the counseling included information regarding diet, physical activity and risk factors for disease and its complications such as alcohol and smoking. The sessions also tackled the correct methods of administrating medications and monitoring plan (frequency and therapeutic goals). The DSME program was adapted by the authors according to the needs of the country. Each patient received the same leaflet to keep for reference. The interviews along with the counselling sessions and evaluation were carried out for around $30 \mathrm{~min}$. The educational counselling sessions were delivered by the trained pharmacists through face-to-face individualized sessions. All pharmacists received a thorough training before the beginning of the study; the same diabetes education and counselling was given to each patient at designated areas.

\section{Knowledge questionnaire}

We used the Diabetes Knowledge Questionnaire (DKQ) ${ }^{[17]}$ to assess the patients' knowledge about diabetes. Questions were translated to Arabic and back-translated to English to ensure translation adequacy and lack of discrepancies. The scale was piloted over 20 individuals to make sure the questions were clear and well understood. The knowledge score was calculated by summing the answers for all questions of the scale. Answer choices were given a numerical value of 1 for having correct knowledge and 0 for lack of knowledge. The total knowledge score ranged between 0 reflecting low / lack of knowledge and 24 reflecting correct / high knowledge. We calculated the reliability of the knowledge scale to assess the quality of our data. We obtained high Cronbach alpha for this scale (0.773). Since we obtained good internal consistency, the results we got from these scales are adequate and reliable.

Data Collection and Study Procedure: The following data collected and completed by the pharmacist for each patient from February to May 2016 through a structured questionnaire.

The questionnaire consisted of the following parts: the first part included questions related to patient demographics such as (age, gender, BMI, educational level) and the second part included questions related to the health status perception. The third part included questions to assess patients knowledge for optimal glucose range, risk factors for diabetes, medications to control patient's own symptoms, correct dose administration, best method to monitor for diabetes, frequency of blood glucose monitoring including HbA1C, frequency for blood pressure monitoring, frequency for kidney monitoring, foot care, eye care, hypoglycemia symptoms management and disease complications. This part also included information for predictor factors proved by literature that can affect diabetes such as smoking, physical status, food and alcohol consumption. In order to collect information regarding predisposing and enabling factors, questions related to payment and insurance information were also collected. Moreover, to access health perceptions and social and behavioral barriers, the questionnaire included the health belief model.

The Health Belief Model (HBM) is a psychological model that attempts to explain and predict health behaviors, this is done by focusing on the attitudes and beliefs of individuals. ${ }^{[18]}$ The HBM is the most effective models of health education and disease as the model identifies four aspects of assessment: perceived susceptibility, perceived severity, perceived benefits and perceived barriers.

The HBM in the questionnaire included questions related to each perception regarding diabetes to know which perception the patients perceived the most and least to affect their health. All data was collected by the questioning of participants in the clinics and pharmacies across the designated areas. According to the patient responses to the third part of the questionnaire, the level of knowledge about diabetes was assessed by the pharmacist before and after the intervention.

The scoring system started with if they knew what type of diabetes they had or not and for this they received 1 point if they knew and no points if they didn't and then counseled about the types. Next they were asked about what factors and foods affect diabetes and for each correct answer they also received one point. They were also asked if they underwent any physical activity, best method for blood glucose testing, how often they checked their blood sugar, HbA1c, kidney function and blood pressure and according to the guideline recommendations they were given a point if correct and no point if incorrect and then counseled correctly as recommended.

Then they were asked about hypoglycemia, what are its symptoms and if they know how to treat, also about foot care, how many times they inspected their feet and how they cared for them, also about eye care and if they examine their eyes, where also a 1 point score was given for each correct answer and zero for incorrect answers along with counseling.

After the questioning and counselling session, the patients were re-asked the same questions of part 3 and scored for each question again. The same 
scoring system was used before and after counseling to assess the patient's awareness. Such format was followed to evaluate the most effective method of counseling in improving the patient's knowledge about diabetes and its treatment, also to enhance the patient-pharmacist relationship.

Another important part which followed the questioning and counselling done in part 3 of the questionnaire was the HBM. It was divided into 4 parts and the patients agreement with each item in each part of the HBM was indicated on a 5 point scale ranging from 1 point (strongly disagree) to 5 points (strongly agree).

The first was perceived susceptibility, where participants were asked about their belief or perceived susceptibility to the disease or its complications (such as "my diabetes would be worse if I did nothing about it". Higher scores indicated the ability of the patient to control his or her diabetes. Second part was perceived severity, where patients rated the seriousness and severity of the disease to their life and future (such as "my diabetes will cause me to be sick a lot". Higher scores here indicated the how serious the patient was about their diabetes and willingness to control it. Third part was the perceived benefits, where the patients showed if following positive health behaviors affected their diabetes positively or not (example "I believe I can control my diabetes". Higher scores indicated the patient's ability to control their diabetes for better outcomes. The fourth part was perceived barriers, where participants rated the items acting as barriers to diabetes management (for instance "I can't pay for my medications" and "I would have to change too many habits and follow my prescription". Higher scores showed more barriers to diabetes management. The HBM part of the questionnaire helped the pharmacists see which perception the patients scored most and least, in order to tackle this perception in further studies.

\section{Ethical Considerations}

The study was reviewed and approved by the Institutional Review Board of the School of Pharmacy at Lebanese International University (LIU). Written informed consent available were obtained from patients.

\section{Statistical analysis}

Statistical analysis was done using the Statistical Package for Social Science (SPSS version 23). Descriptive statistics were mostly used to describe patient characteristics (frequencies and percentages for categorical variables). For categorical variables, the $\chi 2$ and Fisher exact tests were used when applicable. The paired t-test was used to assess the difference before and after intervention. A multivariable linear regression was carried out using the knowledge score as the dependent variable and taking variables that showed a $\mathrm{p}<0.2$ in the bivariate analysis as independent variables. ${ }^{[19,20]}$ Potential confounders may be eliminated only if $\mathrm{p}>0.2$, in order to protect against residual confounding. ${ }^{[1]}$ Significance was defined as a p-value less than 0.05.

\section{RESULTS}

\section{Sociodemographic, social habits and other characteristics}

Sociodemographic, social habits and other characteristics of the participants are summarized in Table 1. A significantly higher proportion of females were unemployed compared to their male counterparts (53.8\% vs 5.6\%), with a significantly higher proportion smoking waterpipe (13.7\% vs $5.6 \%)$. A significantly higher proportion of men has had diabetes for a duration longer than 10 years $(25.8 \%$ vs $14.5 \%)$ and a family history of diabetes $(74.2 \%$ vs $52.1 \%)$. No significant difference was found with all other variables ( $\mathrm{p}>0.05)$.

\begin{tabular}{|c|c|c|c|}
\hline Factor & Male & Female & $p$-value \\
\hline Age category (in years) & & & 0.529 \\
\hline Less than 40 & $12(13.5 \%)$ & $25(21.4 \%)$ & \\
\hline $40-50$ & $26(29.2 \%)$ & $24(20.5 \%)$ & \\
\hline $51-60$ & $23(25.8 \%)$ & $31(26.5 \%)$ & \\
\hline $61-70$ & $22(24.7 \%)$ & $27(23.1 \%)$ & \\
\hline $71-80$ & $6(6.7 \%)$ & $9(7.7 \%)$ & \\
\hline More than 80 & $0(0 \%)$ & $1(0.9 \%)$ & \\
\hline Marital Status & & & 0.151 \\
\hline Single & $15(16.9 \%)$ & $19(16.2 \%)$ & \\
\hline Married & $58(65.2 \%)$ & $71(60.7 \%)$ & \\
\hline Divorced & $8(9 \%)$ & $5(4.3 \%)$ & \\
\hline Widowed & $8(9 \%)$ & $22(18.8 \%)$ & \\
\hline Working status & & & $<0.0001$ \\
\hline Working status & $57(64 \%)$ & $42(35.9 \%)$ & \\
\hline Retired & $27(30.3 \%)$ & $12(10.3 \%)$ & \\
\hline Unemployed & $5(5.6 \%)$ & $63(53.8 \%)$ & \\
\hline Social support & & & 0.235 \\
\hline Living alone & $11(12.4 \%)$ & $9(7.7 \%)$ & \\
\hline Living with a family member & $77(86.5 \%)$ & $108(92.3 \%)$ & \\
\hline Living with friends & $1(1.1 \%)$ & $0(0 \%)$ & \\
\hline Educational level & & & 0.07 \\
\hline Illiterate & $7(7.9 \%)$ & $25(21.4 \%)$ & \\
\hline Primary & $19(21.3 \%)$ & $22(18.8 \%)$ & \\
\hline Secondary & $28(31.5 \%)$ & $32(27.4 \%)$ & \\
\hline University & $35(39.3 \%)$ & $38(32.5 \%)$ & \\
\hline Concomitant chronic diseases & & & 0.068 \\
\hline No & $27(30.3 \%)$ & $50(42.7 \%)$ & \\
\hline Yes & $62(69.7 \%)$ & $67(57.3 \%)$ & \\
\hline Alcohol intake & & & 0.062 \\
\hline No & $78(87.6 \%)$ & $111(94.9 \%)$ & \\
\hline Yes & $11(12.4 \%)$ & $6(5.1 \%)$ & \\
\hline Smoking status & & & $<0.0001$ \\
\hline No & $44(49.4 \%)$ & $80(68.4 \%)$ & \\
\hline Cigarettes & $37(41.6 \%)$ & $21(17.9 \%)$ & \\
\hline Water pipe & $5(5.6 \%)$ & $16(13.7 \%)$ & \\
\hline Both cigarettes and water pipe & $3(3.4 \%)$ & $0(0 \%)$ & \\
\hline Overall health condition & & & 0.505 \\
\hline Excellent & $0(0 \%)$ & $1(0.9 \%)$ & \\
\hline Very good & $19(21.3 \%)$ & $32(27.4 \%)$ & \\
\hline Good & $46(51.7 \%)$ & $58(49.6 \%)$ & \\
\hline Poor & $17(19.1 \%)$ & $22(18.8 \%)$ & \\
\hline Very poor & $7(7.9 \%)$ & $4(3.4 \%)$ & \\
\hline Presence of chronic diseases & & & 0.068 \\
\hline No & $27(30.3 \%)$ & $50(42.7 \%)$ & \\
\hline Yes & $62(69.7 \%)$ & $67(57.3 \%)$ & \\
\hline Medication intake for chronic diseases & & & 0.068 \\
\hline No & $27(30.3 \%)$ & $50(42.7 \%)$ & \\
\hline Yes & $62(69.7 \%)$ & $67(57.3 \%)$ & \\
\hline Duration of diabetes & & & 0.04 \\
\hline$\leq 1$ year & $18(20.2 \%)$ & $41(35 \%)$ & \\
\hline $2-5$ years & $29(32.6 \%)$ & $41(35 \%)$ & \\
\hline $6-9$ years & $19(21.3 \%)$ & $18(15.4 \%)$ & \\
\hline$\geq 10$ years & $23(25.8 \%)$ & $17(14.5 \%)$ & \\
\hline Family history of diabetes & & & 0.001 \\
\hline No & $23(25.8 \%)$ & $56(47.9 \%)$ & \\
\hline Yes & $66(74.2 \%)$ & $61(52.1 \%)$ & \\
\hline
\end{tabular}




\section{Bivariate analysis}

Our study results showed that all items of the knowledge score was increased significantly from pre to post counseling ( $\mathrm{p}<0.05$ for all variables) (Table 2$)$.

\section{Multivariable analysis}

The results of the linear regression taking the knowledge score as the dependent variable, showed that the female gender would significantly increase the knowledge score by 0.625 points $(p=0.001$, Beta $=0.625$, CI 0.250-1.00), whereas living with a family member would significantly decrease the knowledge score by 0.975 points $(\mathrm{p}=0.002$, Beta $=-0.975$, CI -1.601- -0.350) (Table 3).

\section{Table 2: Paired sample t-test of the different variables of} the knowledge score.

\begin{tabular}{|l|l|l|l|l|l|}
\hline Factor & Mean & $\begin{array}{l}\text { Standard } \\
\text { Deviation }\end{array}$ & \multicolumn{2}{l|}{\begin{tabular}{l}
\multicolumn{2}{l|}{ Confidence } \\
Interval
\end{tabular}} & p-value \\
\hline $\begin{array}{l}\text { Type of diabetes } \\
\text { mellitus }\end{array}$ & -.48058 & .50084 & -.54938 & -.41178 & $<0.0001$ \\
\hline $\begin{array}{l}\text { Foods to be eaten: } \\
\text { score over 10 }\end{array}$ & -1.72330 & 1.38146 & -1.91307 & -1.53353 & $<0.0001$ \\
\hline $\begin{array}{l}\text { Foods not to be eaten: } \\
\text { score over 7 }\end{array}$ & -.46117 & .67423 & -.55378 & -.36855 & $<0.0001$ \\
\hline Physical activity & -.35437 & .70928 & -.45180 & -.25694 & $<0.0001$ \\
\hline $\begin{array}{l}\text { Administration of } \\
\text { antidiabetic drugs }\end{array}$ & -.03922 & .19459 & -.06608 & -.01235 & .004 \\
\hline $\begin{array}{l}\text { Best method for } \\
\text { testing blood glucose }\end{array}$ & -.24272 & .42977 & -.30176 & -.18368 & $<0.0001$ \\
\hline $\begin{array}{l}\text { Frequency of blood } \\
\text { glucose measurement }\end{array}$ & -.21359 & .41084 & -.27003 & -.15716 & $<0.0001$ \\
\hline $\begin{array}{l}\text { Frequency of HbA1C } \\
\text { measurement }\end{array}$ & -.33495 & .81417 & -.44679 & -.22311 & $<0.0001$ \\
\hline $\begin{array}{l}\text { Frequency of kidney } \\
\text { function measurement }\end{array}$ & .93204 & 2.60492 & .57421 & 1.28987 & $<0.0001$ \\
\hline $\begin{array}{l}\text { Frequency of } \\
\text { blood pressure } \\
\text { measurement }\end{array}$ & 1.45146 & 1.57885 & 1.23457 & 1.66834 & $<0.0001$ \\
\hline $\begin{array}{l}\text { Know symptoms of } \\
\text { hypoglycemia }\end{array}$ & -.47087 & .50037 & -.53961 & -.40214 & $<0.0001$ \\
\hline $\begin{array}{l}\text { Know how to treat } \\
\text { hypoglycemia }\end{array}$ & -.33981 & .47480 & -.40503 & -.27458 & $<0.0001$ \\
\hline Knowledge score & -1.79902 & 4.08576 & -2.36305 & -1.23499 & $<0.0001$ \\
\hline DMe & & & & & \\
\hline
\end{tabular}

${ }^{*} \mathrm{DM}=$ Diabetes Mellitus

** All variables were tested pre- and post-counseling

\section{Table 3: Linear regression taking the knowledge score as the dependent variable.}

\begin{tabular}{|c|c|c|c|c|c|}
\hline 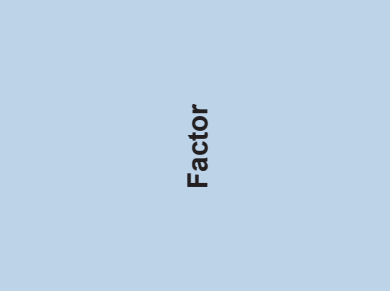 & 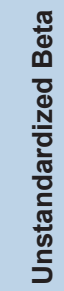 & 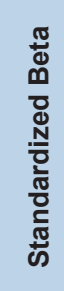 & $\begin{array}{l}\frac{0}{2} \\
\frac{3}{0} \\
\text { อ̇ }\end{array}$ & & \\
\hline Gender (males* ${ }^{*}$ s females) & .625 & .223 & .001 & .250 & 1.000 \\
\hline Living with a family member ( $\mathrm{No}^{*}$ vs yes) & -.975 & -.209 & .002 & -1.601 & -.350 \\
\hline
\end{tabular}

${ }^{*}$ Reference group

\section{HBM questionnaire}

We calculated the reliability of each scale to assess the quality of our data. We obtained high Cronbach alphas for all subscales as follows: susceptibility subscale (0.728), severity subscale (0.774), benefits subscale (0.647) and the barriers subscale (0.629). Since we obtained high internal consistency, the results we obtain from these scales are reliable. The participants' answers are summarized in Table 4.

\section{Correlation between the HBM subscales}

The susceptibility score was significantly and positively correlated with the severity score and the benefits score $(r=0.259$ and $r=0.680)$ respectively, but negatively correlated with the barriers score $(r=-0.290)$. Moreover, the severity score was significantly correlated with the benefits score $(r=0.230)$, whereas the benefits score was significantly but negatively correlated with the barriers score $(r=-0.311)$ (Table 5).

\section{DISCUSSION}

This study attempted to answer two main questions: Does Diabetes SelfManagement Education improve patient knowledge towards diabetes? What are the main social and behavioral barriers that affect patient's compliance or seeking medical advices?

This study found that the program improved patient's knowledge regarding diabetes type II. Thus, patient education about the etiology of diabetes should be addressed and clarified by health care professionals, as should the associated complications of the disease. ${ }^{[2]}$ The future is to test whether these approaches, if adapted to the Lebanese context, will be beneficial and culturally-accepted.

Our findings showed that females had a significantly more increased knowledge score after the intervention compared to their male counterparts, in opposite to previous studies in the United Arab Emirates and Zimbabwe, which found that males had a higher mean knowledge score than females ${ }^{[2-24]}$ but in line with other research. ${ }^{[25-27,28]}$ In addition, a recent study conducted in Lebanon showed no gender difference in terms of knowledge about diabetes.This finding might seem contradictory, but it could be a major indication of lack of access to information about diabetes mellitus, irrespective of a more active information-seeking behavior. It is therefore important that physicians, pharmacists and other health care practitioners realize the importance of gender-sensitive diabetes self-management education (DSME) based on individual needs, which is the cornerstone of care for patients with diabetes as it improves patient outcomes ${ }^{[29]}$ and reduces the global burden of diabetes (IDF, Global burden). ${ }^{[30]}$ Studies have demonstrated that the knowledge of diabetes is limited, with most suggesting educational programs to increase patient awareness about diabetes mellitus to improve their ability to cope with the disease. ${ }^{[31-37]}$ Thus, patient education about the etiology of diabetes should be addressed properly, as should the associated complications of the disease. This can be achieved by encouraging health education in schools and by using the appropriate language and communication tool to educate the public on diabetes. Education should therefore not be limited to clinics and patients with diabetes mellitus only. It is worth mentioning that most of the female patients were married, therefore we assume that females as mothers and wives can be actively involved in increasing awareness for diabetes with their families and children.

In addition patients, who are living with other family members, had a significant lower knowledge score. While family influences the selfmanagement of diabetes, the diabetes of one family member also influences 
Table 4: HBM questionnaire.

\begin{tabular}{|c|c|c|c|c|c|}
\hline Factor & $\begin{array}{l}\text { Strongly } \\
\text { agree }\end{array}$ & Agree & Neutral & Disagree & $\begin{array}{l}\text { Strongly } \\
\text { disagree }\end{array}$ \\
\hline \multicolumn{6}{|l|}{ Susceptibility } \\
\hline My diabetes is well controlled & $8(3.9 \%)$ & $42(20.4 \%)$ & $43(20.9 \%)$ & $90(43.7 \%)$ & $23(11.2 \%)$ \\
\hline My diabetes would be worse if I did nothing about it & $0(0 \%)$ & $3(1.5 \%)$ & $9(4.4 \%)$ & $96(46.6 \%)$ & $98(47.6 \%)$ \\
\hline I believe that my diet (medications) will help prevent diseases and complications related to diabetes & $0(0 \%)$ & $2(1 \%)$ & $9(4.4 \%)$ & $101(49 \%)$ & $94(45.6 \%)$ \\
\hline \multicolumn{6}{|l|}{ Severity } \\
\hline My diabetes is no problem to me as long as I feel alright & $13(6.3 \%)$ & $88(42.7 \%)$ & $32(15.5 \%)$ & $64(31.1 \%)$ & $9(4.4 \%)$ \\
\hline My diabetes will cause me to be sick a lot & $0(0 \%)$ & $55(26.7 \%)$ & $12(5.8 \%)$ & $60(29.1 \%)$ & $79(38.3 \%)$ \\
\hline I believe I will always need my diabetes diet (medications) & $2(1 \%)$ & $10(4.9 \%)$ & $11(5.3 \%)$ & $99(48.1 \%)$ & $84(40.8 \%)$ \\
\hline \multicolumn{6}{|l|}{ Benefits } \\
\hline I believe I can control my diabetes & $0(0 \%)$ & $40(19.4 \%)$ & $50(24.3 \%)$ & $98(47.6 \%)$ & $18(8.7 \%)$ \\
\hline If I change my eating habits, it will probably help me & $0(0 \%)$ & $7(3.4 \%)$ & $19(9.2 \%)$ & $142(68.9 \%)$ & $38(18.4 \%)$ \\
\hline My medications would make me feel better & $0(0 \%)$ & $7(3.4 \%)$ & $4(1.9 \%)$ & $129(62.6 \%)$ & $66(32 \%)$ \\
\hline \multicolumn{6}{|l|}{ Barriers } \\
\hline I would have to change too many habits and follow my diet (medications) & $0(0 \%)$ & $42(20.4 \%)$ & $19(9.2 \%)$ & $112(54.4 \%)$ & $33(16 \%)$ \\
\hline It has been difficult following the diet (medications) prescribed to me & $2(1 \%)$ & $54(26.2 \%)$ & $24(11.7 \%)$ & $98(47.6 \%)$ & $28(13.6 \%)$ \\
\hline I cannot understand what the doctor told me about my diet (medications) & $34(16.5 \%)$ & $128(62.1 \%)$ & $26(12.6 \%)$ & $16(7.8 \%)$ & $2(1 \%)$ \\
\hline Taking my medications interferes with my normal daily activities & $3(1.5 \%)$ & $121(58.7 \%)$ & $23(11.2 \%)$ & $51(24.8 \%)$ & $8(3.9 \%)$ \\
\hline I can't find my medications easily & $45(21.8 \%)$ & $134(65 \%)$ & $23(11.2 \%)$ & $4(1.9 \%)$ & $0(0 \%)$ \\
\hline I can't pay for my medications & $17(8.3 \%)$ & $118(57.3 \%)$ & $45(21.8 \%)$ & $26(12.6 \%)$ & $0(0 \%)$ \\
\hline I find difficulties to reach the hospital or doctor to do further check up & $41(19.9 \%)$ & $122(59.2 \%)$ & $20(9.7 \%)$ & $22(10.7 \%)$ & $1(0.5 \%)$ \\
\hline
\end{tabular}

Table 5: Correlation between all subscales of the HBM model.

\begin{tabular}{|l|l|l|l|l|l|}
\hline \multicolumn{2}{|c|}{} & Susceptibility score & Severity score & Benefits score & Barriers score \\
\hline \multirow{3}{*}{ Susceptibility score } & Pearson Correlation & 1 & $.259^{*}$ & .680 & -.290 \\
\cline { 2 - 6 } & p-value & - & $<0.0001$ & $<0.0001$ & $<0.0001$ \\
\hline \multirow{3}{*}{ Severity score } & Pearson Correlation & .259 & 1 & .230 & -.046 \\
\cline { 2 - 6 } & p-value & $<0.0001$ & - & .001 & .509 \\
\hline \multirow{2}{*}{ Benefits score } & Pearson Correlation & .680 & .230 & 1 & -.311 \\
\cline { 2 - 6 } & p-value & $<0.0001$ & .001 & - & $<0.0001$ \\
& Pearson Correlation & -.290 & -.046 & -.311 & 1 \\
\cline { 2 - 6 } & $p$-value & $<0.0001$ & .509 & $<0.0001$ & - \\
\hline
\end{tabular}

other members of the family. Parents of the children's with diabetes confess a change in their life after the diagnosis of diabetes and describe it as not easy as before. Parents also have long-term emotional responses to the diabetes even several years after diagnosis. ${ }^{[38-40]}$ We hypothesize that this might be due to the fact that they are dependent on other family members. Family life is very important in the Lebanese culture. Family functioning is associated with the values of collectivism in the Lebanese society. One person's family functioning is indicative of their individual status and identity. ${ }^{[4]}$

\section{Health Belief Model}

According to the health belief model, most of the respondents don't perceive that their disease will progress if they didn't take their medications or comply with diet or physical activity. Those findings shed the lights on the major barriers that affect patient's compliance either on diets or intake of the medications. Stressing on these barriers through the intervention can help the patients to overcome such barriers. A follow up study to monitor the changes using the health belief model after the intervention will aid if the program was effective in changing people perception on the severity and benefits.
As the findings show, perceived severity and perceived benefits were significantly related to diabetes management. This may be explained by the fact that not all the constructs of HBM will directly affect diabetes management. Rather, other factors, such as socio-demographic characteristics, diabetes knowledge, perception, psychosocial factors, patients' factors and cultural beliefs, ${ }^{[42-43]}$ will have to be all present to activate the beliefs.

Other studies also confirm the impact of self-efficacy in increasing self-care including Didarlu et al. ${ }^{[4]}$ that reported self-efficacy as a predictive factor of self-care behavior in diabetic patients. Also in a study by Henrietta ${ }^{[45]}$ and Wen et al. ${ }^{[46]}$ similar results with the findings of the present study were reported. The self-efficacy is extremely important factor of behavior that is required to solve the problem in difficult conditions. ${ }^{[4]}$ Self-care behaviors require awareness, skill and different sources. Further, it has been shown that there was a negative relationship between barriers and self-efficacy; patients perceiving fewer barriers were more confident in diabetes self-care behaviors. ${ }^{[48]}$

The present study suggests that people with diabetes in Lebanon have high self-efficacy. Based on this construct, patients might believe that an action 


\section{El-Haddam, et al.: DSME and Diabetic Patients' Knowledge}

could benefit them and they may act accordingly to achieve the desired outcomes due to a high level of confidence in executing the necessary actions. ${ }^{[49]}$ Perceived barriers shown to be negatively independent to other factors within the HBM model. Thus, to increase self-efficacy in diabetes self-care behaviors, patients' barriers should be addressed by developing appropriate knowledge and skills. With the increased cost of living in Lebanon and the restrictions of healthcare plans, patient counseling and diabetes education provided in community pharmacies, by licensed pharmacists, constitute one of many and probably the most efficient interventions. Patients may consult and seek advice from community pharmacists without prior appointment unlike other health professionals. Pharmacists usually have long-term fiducial relationships with most of their chronic patients including those with diabetes. They do not only dispense medications, but play a dynamic role in quality diabetes care through detection, referral of individuals at risk of diabetes and education of patients about their medications' dosage, side effects, administration and monitoring parameters. ${ }^{[50-51]}$ Therefore, this program might aid to increase patient's awareness through pharmacist counseling.

\section{Limitations}

The study didn't include a control group as major limitation for this study. The presence of the control group would help compare between different methods of interventions. In addition, patient's willingness to participate in the study also might affect the improvement in the score before and after the intervention. The major advantage of this study that it used the same validated measurement before and after the intervention and this limited instrumentation and measurement biases within the study. Nevertheless the program sustainability of the program cannot be detected which is also a limitation for this study design.

\section{CONCLUSION}

This study has demonstrated that a formal diabetes education program can effectively increase patients' diabetes knowledge. According to the health belief model, the main barriers that the patients don't comply with medication and diet since they don't perceive that the disease is severe or they don't believe that medication and diet will decrease the progression of the disease. Therefore this program will heighten patient knowledge about the disease and its complications as well as it will highlight on the importance of diet and medications in preventing patient deterioration and disease progression.

\section{ACKNOWLEDGEMENT}

Authors would like to thank everyone who has supported the creation of this work. Special thanks to the patients for agreeing to participate in the study.

\section{CONFLICTS OF INTEREST}

The authors declare no conflict of interest.

\section{ABBREVIATIONS}

None

\section{REFERENCES}

1. Global report on diabetes. World Health Organization, Geneva, 2016 (http:// www.who.int/diabetes/global-report/en/.

2. American Diabetes Association. Standards of medical care in diabetes-2015: summary of revisions. Diabetes Care. 2015;38:S4. Available from: http://care. diabetesjournals.org/content/38/Supplement_1/S4.short.

3. Mathers $C D$, Loncar D. Projections of global mortality and burden of disease from 2002 to 2030. PLoS Med. 2006;3(11):e442.

4. Alhyas L, McKay A, Majeed A. Prevalence of type 2 diabetes in the States of the co-operation council for the Arab States of the Gulf: a systematic review.
PLoS One. 2012;7(8):e40948.

5. Cho NH, Colagiuri S, Distiller L, Dong B, Dunning T, Gadsby R, et al. International Diabetes Federation: Global guideline for managing older people with type 2 diabetes. 2013. Brussels: International Diabetes Federation, Available from: https://www.idf.org/sites/default/files/IDF-Guideline-for-older-people-T2D.pdf.

6. Guariguata L, Whiting DR, Hambleton I, Beagley J, Linnenkamp U, Shaw JE. Global estimates of diabetes prevalence for 2013 and projections for 2035. Diabetes Research and Clinical Practice. 2014;103(2):137-49.

7. Boutayeb A, Lamlili ME, Boutayeb W, Maamri A, Ziyyat A, Ramdani N. The rise of diabetes prevalence in the Arab region. Open Journal of Epidemiology. 2012;2(02):55.

8. Funnell MM, Brown TL, Childs BP, Haas LB, Hosey GM, Jensen B, et al. National standards for diabetes self-management education. Diabetes Care. 2007;30(6):1630-7.

9. Parker AR, Byham-Gray L, Denmark R, Winkle PJ. The effect of medical nutrition therapy by a registered dietitian nutritionist in patients with prediabetes participating in a randomized controlled clinical research trial. J Acad Nutr Diet. 2014;114(11):1739-48.

10. Butcher MK, Vanderwood KK, Hall TO, Gohdes D, Helgerson SD, Harwell TS. Capacity of diabetes education programs to provide both diabetes selfmanagement education and to implement diabetes prevention services. J Public Health Manag Pract. 2011;17(3):242-7.

11. Mehuys E, Bortel LV, Bolle LD, Tongelen IV, Annemans L, Remon JP, et al. Effectiveness of a community pharmacist intervention in diabetes care: a randomized controlled trial. J Clin Pharm Therapeu. 2011;36(5):602-613.

12. Mazroui A, Rashid N, Kamal MM, Ghabash NM, Yacout TA, Kole PL, et al. Influence of pharmaceutical care on health outcomes in patients with Type 2 diabetes mellitus. British Journal of Clinical Pharmacology. 2009;67(5):547-57.

13. Jarab AS, Alqudah SG, Mukattash TL, Shattat G, Al-Qirim T. Randomized controlled trial of clinical pharmacy management of patients with type 2 diabetes in an outpatient diabetes clinic in Jordan. J Manag Care Pharm. 2012;18(7):516-26.

14. Mehio SA, Nasreddine L, Mokdad AH, Adra N, Tabet M, Hwalla N. Nutrition transition and cardiovascular disease risk factors in Middle East and North Africa countries: reviewing the evidence. Ann Nutr Metab. 2010;57(3-4):193-203.

15. Sibai AM, Zard C, Adra N, Baydoun M, Hwalla N. Variations in nutritional status of elderly men and women according to place of residence. Gerontology. 2003;49(4):215-24.

16. Centers for disease control and prevention. Epi info 7 available on http://wwwn. cdc.gov/epiinfo/7/index.htm.

17. Menino E, Dos M, Clarisse M. Validation of Diabetes Knowledge Questionnaire (DKQ) in the Portuguese Population. Diabetes Obes Int J. 2017;2(1):1-8.

18. Pilling S, Bebbington P, Kuipers E, Garety P, Geddes J, Orbach G, et al. Psychological treatments in schizophrenia: I. Meta-analysis of family intervention and cognitive behaviour therapy. Psychol Med. 2002;32(5):763-82.

19. Mickey RM, Greenland $S$. The impact of confounder selection criteria on effect estimation. Am J Epidemiol. 1989;129(1):125-37.

20. Bursac Z, Gauss CH, Williams DK, Hosmer DW. Purposeful selection of variables in logistic regression. Source Code for Biology and Medicine. 2008;3(1):17.

21. Maldonado G, Greenland S. Simulation study of confounder-selection strategies. Am J Epidemiol. 1993;138(11):923-36.

22. Haas L, Maryniuk M, Beck J, Cox CE, Duker P, Edwards L, et al. National standards for diabetes self-management education and support. Diabetes Care. 2014;37(Suppl 1):S144-53.

23. Ali M, Khalid GH, Pirkani GS. Level of health education in patients with type II diabetes mellitus in Quetta. J Pak Med Assoc. 1998;48(11):334-6.

24. Mufunda E, Wikby K, Bjorn A, Hjelm K. Level and determinants of diabetes knowledge in patients with diabetes in Zimbabwe: a cross-sectional study. Pan Afr Med J. 2012;13:78.

25. Hjelm K, Mufunda E. Zimbabwean diabetics' beliefs about health and illness: an interview study. BMC Int Health Hum Rights. 2010;10(1):7.

26. Mufunda E, Albin B, Hjelm K. Differences in health and illness beliefs in zimbabwean men and women with diabetes. Open Nurs J. 2012;6:117-25.

27. Hjelm K, Nambozi G. Beliefs about health and illness: a comparison between Ugandan men and women living with diabetes mellitus. Int Nurs Rev. 2008;55(4):434-41.

28. Lamis R. Karaoui, Mary E. Deeb, Layal Nasser, Souheil Hallit. Knowledge and 


\section{El-Haddam, et al.: DSME and Diabetic Patients' Knowledge}

practice of patients with diabetes mellitus in Lebanon: a cross-sectional study. BMC Public Health. 2018;18:525.

29. Al-Adsani AM, Moussa MA, Al-Jasem LI, Abdella NA, Al-Hamad NM. The level and determinants of diabetes knowledge in Kuwaiti adults with type 2 diabetes. Diabetes Metab. 2009;35(2):121-8.

30. Muller DR, Roder V, Brenner HD. Effectiveness of Integrated Psychological Therapy for schizophrenia patients. A meta-analysis including 28 independent studies. Nervenarzt. 2007;78(1):62-73.

31. Al-Maskari F, El-Sadig M, Al-Kaabi JM, Afandi B, Nagelkerke N, Yeatts KB. Knowledge, attitude and practices of diabetic patients in the United Arab Emirates. PLoS One. 2013;8(1):e52857.

32. Sweileh WM, Zyoud SH, Abu NRJ, Deleq MI, Enaia MI, Nassar SM, et al. Influence of patients' disease knowledge and beliefs about medicines on medication adherence: findings from a cross-sectional survey among patients with type 2 diabetes mellitus in Palestine. BMC Public Health. 2014;14(1):94.

33. Elliott JA, Abdulhadi NN, Al-Maniri AA, Al-Shafaee MA, Wahlstrom R. Diabetes self-management and education of people living with diabetes: a survey in primary health care in Muscat Oman. PLoS One. 2013;8(2):e57400.

34. Foma MA, Saidu Y, Omoleke SA, Jafali J. Awareness of diabetes mellitus among diabetic patients in the Gambia: a strong case for health education and promotion. BMC Public Health. 2013;13(1):1124.

35. Demaio AR, Otgontuya D, Courten MD, Bygbjerg IC, Enkhtuya P, Oyunbileg J, et al. Exploring knowledge, attitudes and practices related to diabetes in Mongolia: a national population-based survey. BMC Public Health. 2013;13(1):236.

36. Thepwongsa I, Kirby C, Paul C, Piterman L. Management of type 2 diabetes: Australian rural and remote general practitioners' knowledge, attitudes and practices. Rural Remote Health. 2014;14(1):2499.

37. Zhou $Y$, Liao L, Sun M, He G. Self-care practices of Chinese individuals with diabetes. Exp Ther Med. 2013;5(4):1137-42.

38. Bowes S, Lowes L, Warner J, Gregory JW. Chronic sorrow in parents of children with type 1 diabetes. J Adv Nur. 2009;65(5):992-1000.

39. Wennick A, Hallström I. Families' lived experience one year after a child was diagnosed with type 1 diabetes. J Advanced Nur. 2007;60(3):299-307.

40. Marshall M, Carter B, Rose K, Brotherton A. Living with type 1 diabetes: perceptions of children and their parents. J Clin Nur. 2009;18(12):1703-10.

41. Kazarian SS. Family functioning, cultural orientation and psychological well-being among university students in Lebanon. J Soc Psychol. 2005;145(2):141-54.

42. Arndt V, Sturmer T, Stegmaier C, Ziegler H, Dhom G, Brenner H. Sociodemographic factors, health behavior and late-stage diagnosis of breast cancer in Germany: a population-based study. J Clin Epidemiol. 2001;54(7):719-27.

43. Williams NJ, Whittle JG, Gatrell AC. The relationship between socio-demographic characteristics and dental health knowledge and attitudes of parents with young children. Br Dent J. 2002;193(11):651-4

44. Didarloo A, Shojaeizadeh D, Asl RG, Habibzadeh H, Niknami S, Pourali R. Prediction of self-management behavior among Iranian women with type 2 diabetes: application of the theory of reasoned action along with self-efficacy (etra). Iranian Red Crescent Med J. 2012;14(2):86.

45. Hanna $\mathrm{HH}$. The influence of self-efficacy and spirituality on self-care behaviors and glycemic control in older African Americans with type 2 diabetes. Barry University School of Nursing. 2006

46. Wen LK, Shepherd MD, Parchman ML. Family support, diet and exercise among older Mexican Americans with type 2 diabetes. Diabetes Educ. 2004;30(6):980-93.

47. Jalilian F, Mirzaei AM, Emdadi S, Nasirzadeh M, Barati B, Hatamzadeh N. The quality of life of women with type 2 diabetes: the study of self-efficacy. Health System Research. 2012;7(6):1013-9.

48. Aljasem LI, Peyrot M, Wissow L, Rubin RR. The impact of barriers and self-efficacy on self-care behaviors in type 2 diabetes. Diabetes Educ. 2001;27(3):393-404.

49. Bandura A. Self-efficacy: toward a unifying theory of behavioral change. Psychol Rev. 1977;84(2):191-215.

50. Campbell RK. Role of the pharmacist in diabetes management. Am J Health Syst Pharm. 2002;59(Suppl 9):S18-21.

51. Smith M. Pharmacists' role in improving diabetes medication management. J Diabetes Sci Technol. 2009;3(1):175-9.

Cite this article as: El-Haddam A, Hallit S, Raad EB. Can Diabetes Self-Management Program Improve Patients' Knowledge? A Real Life Evaluation Study of Lebanese Diabetic Adults. J Pharm Pract Community Med. 2018;4(3):137-43. 